\title{
Combined high-pressure cell-ultrahigh vacuum system for fast testing of model metal alloy catalysts using scanning mass spectrometry
}

Johansson, Martin; Jørgensen, Jan Hoffmann; Chorkendorff, Ib

Published in:

Review of Scientific Instruments

Link to article, DOI:

$10.1063 / 1.1753677$

Publication date:

2004

Document Version

Publisher's PDF, also known as Version of record

Link back to DTU Orbit

Citation (APA):

Johansson, M., Jørgensen, J. H., \& Chorkendorff, I. (2004). Combined high-pressure cell-ultrahigh vacuum system for fast testing of model metal alloy catalysts using scanning mass spectrometry. Review of Scientific Instruments, 75(6), 2082-2093. https://doi.org/10.1063/1.1753677

\section{General rights}

Copyright and moral rights for the publications made accessible in the public portal are retained by the authors and/or other copyright owners and it is a condition of accessing publications that users recognise and abide by the legal requirements associated with these rights.

- Users may download and print one copy of any publication from the public portal for the purpose of private study or research.

- You may not further distribute the material or use it for any profit-making activity or commercial gain

- You may freely distribute the URL identifying the publication in the public portal 


\title{
Combined high-pressure cell-ultrahigh vacuum system for fast testing of model metal alloy catalysts using scanning mass spectrometry
}

\author{
M. Johansson, ${ }^{\text {a) }}$ J. Hoffmann Jørgensen, and I. Chorkendorff \\ Interdisciplinary Research Center for Catalysis (ICAT), Department of Physics and Department of Chemical \\ Engineering, Technical University of Denmark (DTU), DK-2800 Kgs. Lyngby, Denmark
}

(Received 13 August 2003; accepted 23 March 2004; published online 24 May 2004)

\begin{abstract}
An apparatus for fabrication, surface analysis in ultrahigh vacuum, and testing of the catalytic activity of model metal alloy catalysts is described. Arrays of model catalysts are produced by electron-beam deposition of up to four metals simultaneously onto a substrate. The surface analysis techniques available are scanning electron microscopy, x-ray photoemission spectroscopy, ion scattering spectroscopy, Auger electron spectroscopy, sputter profiling, and temperature programmed desorption. The catalytic activity of the model catalysts is tested individually by scanning a combined gas delivery and gas sampling device over the sample surface. The gas sampled is analyzed with mass spectrometry. Experiments can be made at pressures up to 1 bar and temperatures up to $500^{\circ} \mathrm{C}$. It is shown that the lateral resolution is better than $0.2 \mathrm{~mm}$ and that up to 20 circular spots, $1 \mathrm{~mm}$ in diameter, can be studied on a substrate $10 \mathrm{~mm}$ in diameter. A high pressure cell with an all-metal sealed ultrahigh vacuum lock is also described as part of the work.
\end{abstract} (C) 2004 American Institute of Physics. [DOI: 10.1063/1.1753677]

\section{INTRODUCTION}

Since the mid-1990s a range of methodologies has evolved for high-throughput synthesis and screening of heterogeneous catalysts. ${ }^{1,2}$ The objective has been to speed up the discovery process and to lower the development time for new catalysts and materials in general. One example of such an approach is "scanning mass spectrometry," which is performed by integrating gas delivery and spatially resolved gas sampling into a probe that functions over an array of catalysts on a sample plate. ${ }^{3-5}$

High-throughput screening is usually performed on hundreds or even thousands of catalyst samples per day and deeper insight must unfortunately be sacrificed for the sake of speed of testing, since there is no time or equipment for actually performing a detailed study of the composition and surface morphology of the samples responsible for any observed reactivity or lack of same. Nor does the short time interval used for testing $(\sim 30 \mathrm{~s})$ allow detection of long-term instability or the required induction period of the model catalyst. From experience gained from high-pressure experiments on single crystals, even the smallest amounts of impurities may cause tremendous problems. Since the surface area of the catalyst is small compared to the reactor volume, high sensitivity to contamination can be expected also in highthroughput experiments. This could easily lead to erroneous interpretation of the results obtained in high-throughput screening, in the sense that a good catalyst may appear to be inactive either because of contamination, or because it was in an inactive state at the time of measurement.

Metal alloys, often supported on other materials, find extensive use as commercial catalysts. ${ }^{6}$ Surface science studies have previously been used to design a new steam-

\footnotetext{
a) Author to whom correspondence should be addressed; electronic mail: martin.johansson@fysik.dtu.dk
}

reforming catalyst based on surface alloying of $\mathrm{Au}$ and $\mathrm{Ni}^{7}$ Theoretical calculations can be used to predict changes in surface composition related to segregation and alloying. ${ }^{8,9}$ From this and predicted shifts in the $d$-band center of various transition metals one can obtain useful trends in accompanying changes in reactivity ${ }^{10}$ by, for example, having one metal alloyed into the surface of another or simply having one metal forming a pseudomorphic overlayer on another metal. ${ }^{11}$ Recently, theories on universalities in catalysis have been published. ${ }^{12}$ All these theoretical data form a very good basis for identifying interesting metal alloy systems for further investigation.

Unfortunately, the calculations do not yet provide all the information necessary for identifying a viable catalyst. First of all, the calculations merely provide trends, rather than actual accurate turnover frequencies since the activation barriers involved cannot (yet) be determined with sufficient accuracy. Second, the stability of the alloy under the influence of the chemical potential of the reactants and product must be taken into consideration, ${ }^{13}$ since such phenomena can change the surface composition and structure completely. Detailed investigation of the reaction pathway using density functional theory is getting close to having the necessary prediction power, but is still limited since the calculations are very time consuming, even on the fastest computers and, worse, depend on input for the reaction pathway and surface composition. Thus, there is still a need to obtain basic information on the reactivity and composition of catalyst surfaces which have experienced reaction conditions at high pressures.

In order to close the gap between truly high-throughput screening and the slow, but very well-defined, single crystal work usually performed in ultrahigh vacuum, we have designed an apparatus which can synthesize and test of the order of 20 model metal alloy catalysts, without losing the 
capabilities for characterization using standard surface analysis methods.

The apparatus consists of a conventional ultrahigh vacuum surface analysis and metal deposition chamber connected to a high-pressure cell by a vacuum lock. The vacuum lock was developed in our laboratory and is all metal sealed. It allows ultrahigh vacuum to be maintained in the surface analysis chamber while the pressure in the high-pressure cell is 1 bar.

The model catalysts are produced by electron-beam deposition of up to four metals simultaneously. Typically, an array of 10-20 circular spots $1 \mathrm{~mm}$ in diameter is deposited on, for example, a preoxidized aluminum single crystal.

The surface analysis techniques available as part of the apparatus are x-ray photoemission spectroscopy (XPS), ion scattering spectroscopy (ISS) and Auger electron spectroscopy (AES). Imaging AES can be used to map the distribution of elements on the sample surface. Scanning electron microscopy (SEM) is used for orientation and alignment purposes, as well as for studies of the surface structure of the catalysts. Sputter profiling with AES and temperature programmed desorption (TPD) can also be performed.

A gas sampling/gas delivery device for scanning mass spectrometry is mounted on the high-pressure cell so that the reactivity of the alloy spots can be tested sequentially and individually. Experiments can be performed at pressures up to $1 \mathrm{bar}$ and temperatures up to $500{ }^{\circ} \mathrm{C}$ for an extended period of time, often more than $24 \mathrm{~h}$. It is well known that for many catalysts there is substantial rearrangement of the surface composition and structure before the active surface appears. Thus, strong emphasis has been given to continuous, high-pressure operation to enable investigations of long-term effects like segregation, alloying, phase separation, deactivation, and poisoning of the model catalysts.

The gas sampling/gas delivery device consists of a concentric arrangement of an inner quartz tube and an outer steel tube. Gas is blown toward the sample surface through the steel tube so that stagnation-like flow is formed. The end of the quartz tube closest to the sample was melted to a capillary leak. ${ }^{14}$ The quartz capillary leak is used to sample the gas close to the sample surface, and the sampled gas is then analyzed with mass spectrometry. When the device is positioned over a catalyst spot it is thus possible to study the products formed, whereas products formed on adjacent spots are washed away by the gas flow. The entire gas sampling/ gas delivery device can be scanned over the sample surface to measure the local catalytic activity.

The lateral resolution of the high-pressure measurements is shown to be better than $0.2 \mathrm{~mm}$. It seems that the spillover of products from one spot to another is negligible if the distance between the spots is more than $0.7 \mathrm{~mm}$, at least under the conditions tested so far. This means that up to 20 metal alloy spots of $1 \mathrm{~mm}$ diameter can be studied simultaneously on a substrate $10 \mathrm{~mm}$ in diameter. A complete measurement cycle consisting of sample preparation, metal deposition, surface characterization, high-pressure testing, and postreaction studies of the model catalysts takes about one week to perform. This is at least an order of magnitude faster than in conventional work on single crystals where surface

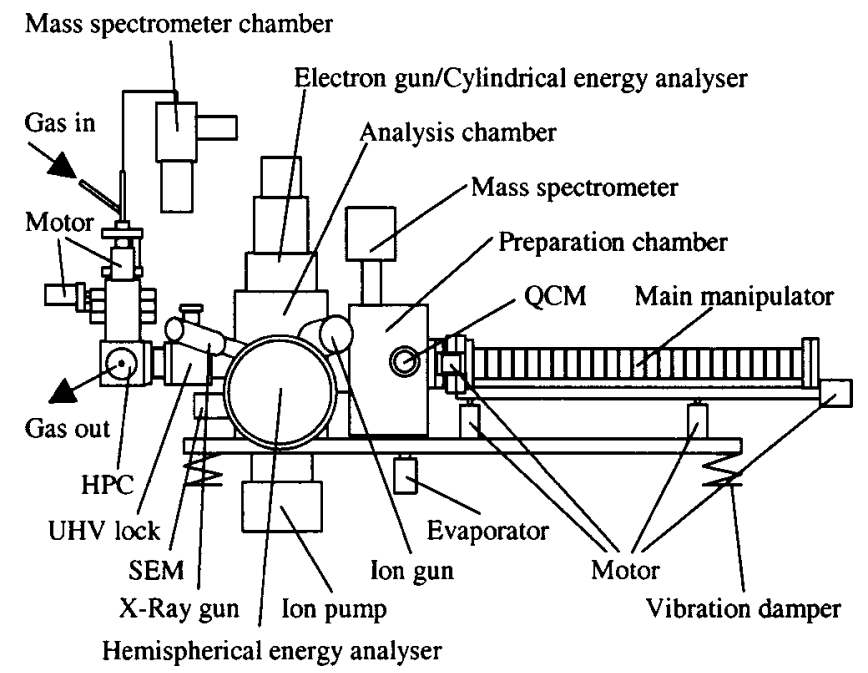

FIG. 1. Schematic of the apparatus. HPC is the high-pressure cell and QCM the quartz crystal microbalance thickness monitor. SEM indicates the position of the SED detector. The main turbo pump is mounted on the opposite side of the sample manufacturing chamber. There is also a flood ion gun mounted on the sample manufacturing chamber (not shown), which is used to clean the samples.

analysis in ultrahigh vacuum (UHV) is combined with measurements at high pressure. The reason for this gain in time is that the time actually spent on manufacturing and analysis of the individual model catalyst is small compared to the amount of time spent obtaining vacuum, cleaning the sample, positioning the sample, warming up and calibrating the analysis equipment, etc. The drawback of the method used in this work is, of course, that the model catalysts obtained by evaporation of metals do not, in general, have a well-defined surface structure.

Some preliminary results on $\mathrm{CO}$ oxidation and hydrogen-deuterium exchange on $\mathrm{Pd}$ and $\mathrm{Pd} / \mathrm{Ni}$ alloys are shown as examples of the performance of the apparatus.

\section{DESCRIPTION OF THE APPARATUS}

The apparatus consists of three basic parts: the sample preparation chamber, the surface analysis chamber, and the high-pressure cell; see Fig. 1. In addition to these basic parts there is also a separate ultrahigh vacuum chamber that contains the mass spectrometer used for the high-pressure measurements and a gas handling system to provide gases for the high-pressure experiments. The sample is mounted at the end of a manipulator arm which allows the sample to be moved throughout the entire apparatus. An electron-beam evaporator is used to manufacture samples. The apparatus includes equipment for several surface sensitive analysis techniques: AES, imaging AES, SEM, XPS, ISS, and TPD. A sputter gun for cleaning the samples and sputter profiling is also mounted.

\section{A. Ultrahigh vacuum system for surface analysis and sample preparation}

The preparation chamber and the surface analysis chamber are parts of the same ultrahigh vacuum chamber. (There is no valve between them.) The chamber is pumped by a Varian 550 l/s turbo pump and a Physical Instruments (PHI) 
combined $220 \mathrm{l} / \mathrm{s}$ ion pump and titanium sublimation pump. After bakeout at $170{ }^{\circ} \mathrm{C}$ the system can maintain pressure of less than $1 \times 10^{-10}$ Torr.

Besides the locked position in the high-pressure cell, there are four stages along the $x$ path of the manipulator: evaporation, Ar sputtering, TPD, and surface analysis (AES, SEM, XPS, and ISS). The first three stages are located in the preparation chamber; see Fig. 1.

In the first stage, metal deposition is done using an Oxford Applied Research H-PEB4 electron-beam evaporator capable of coevaporation from four different pockets. Each pocket has its own power supply capable of up to $200 \mathrm{~W}$ emission power. The H-PEB4 has a water cooled hearth, resulting in a moderate pressure increase during evaporation. The evaporation rate is monitored by a Maxtek TM-400 thickness monitor and SH-102 sensor head. The water cooled sensor head and a mask with holes for deposition of 1, 2, or $3 \mathrm{~mm}$ diam spots are placed on a linear manipulator. In this way either one of the holes or the thickness monitor can be positioned over the evaporator. The device can be retracted completely from the path of the manipulator arm. A shield is mounted on the evaporator head in order to screen other parts of the system from the evaporated material.

In the second stage, the sample surface can be sputtered clean by a Leybold IQE 10/35 $5 \mathrm{kV}$ sputter ion gun.

In the third stage, TPD is performed using a Spectra Microvision Plus quadrupole residual gas analyzer (RGA) with a secondary electron multiplier and a Faraday cup. It is mounted inside a differentially pumped "nose" with inlet diameter of $2 \mathrm{~mm}$. By moving the sample under the nose TPD can be performed on one spot at a time.

The fourth stage contains the surface analysis instruments. The equipment for AES, SEM, XPS, and ISS is all aligned to focus onto the same point, although the sample has to be turned $90^{\circ}$ to face the hemispherical energy analyzer used for XPS and ISS.

A Physical Instruments model 25-120 A scanning auger microprobe with a single pass cylindrical mirror analyzer (CMA) and an electron gun with maximum beam energy of $25 \mathrm{kV}$ is used for AES and imaging AES. The beam diameter of the electron gun is $350 \AA$ at $10 \mathrm{kV}$.

SEM images are generated from electrons picked up by a secondary electron detector (SED). There is also an amplifier for the current running through the sample which can be used to obtain absorbed current images of the sample. The maximum size of the area scanned by the AES electron gun is about $2 \times 2 \mathrm{~mm}^{2}$. Secondary electrons can also be generated by a separate electron gun (Vacuum Science Workshop, maximum $5 \mathrm{kV}$ beam energy) mounted $38^{\circ}$ from the $Y Z$ plane and $35^{\circ}$ below the $X Y$ plane. In this way it is possible to view the entire sample in one SEM image.

The hemispherical analyzer used for XPS and ISS measurements is a Specs Phoibos 100 with single channel detector. The X-ray source used for XPS is a Specs RQ 20/38 (with a dual $\mathrm{Al} / \mathrm{Mg}$ anode) mounted at an angle of $54.7^{\circ}$ from the analyzer. A PHI model 04-303 ion gun is placed at a $130^{\circ}$ scattering angle for ISS.

A T-shaped stabilizer mounted on a rotational feedthrough can be placed as a support under the manipula-

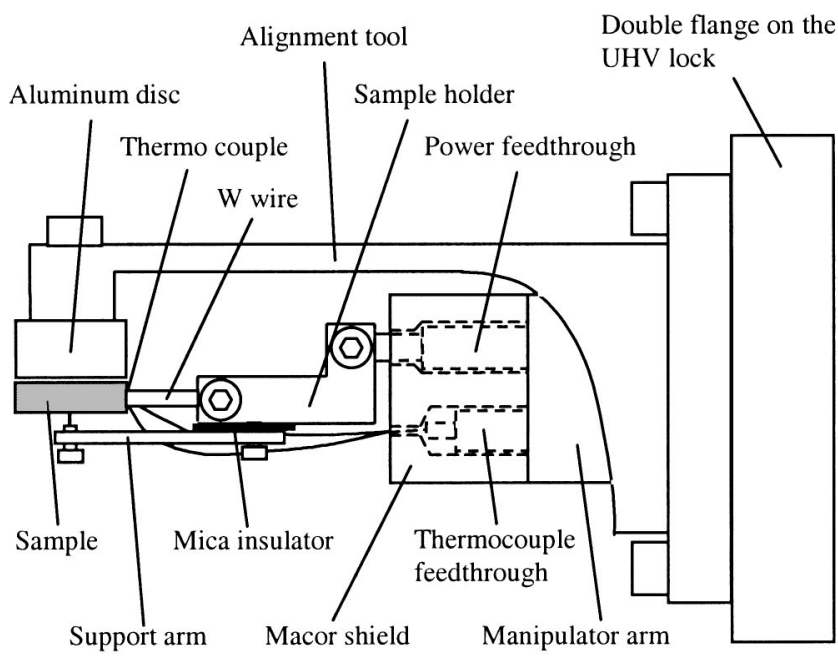

FIG. 2. Sample mounting and alignment of the sample to the $x-y$ plane of motion of the gas sampling device. The sample alignment tool is mounted on the double flange of the UHV lock instead of the high pressure cell.

tor arm. In order to further reduce vibrations the entire apparatus rests on a frame supported by the vibrational damping columns of a PHI Multiprobe 600.

\section{B. Main manipulator and sample mounting}

The manipulator arm is made from a steel tube of length $1.2 \mathrm{~m}$ and outer diameter of $25 \mathrm{~mm}$. It is mounted on a horizontal $x y z \vartheta$ manipulator with an $x$ stroke of $870 \mathrm{~mm}$. The arm is supported at the $y z$ stage by four stainless steel precision bearings $45^{\circ}$ off vertical and at the outer end where it is tightened to the rotating platform. The rotating platform is a two-stage Thermionics RNN 250/FA differentially pumped rotary seal.

Motion in the $x, y$, and $z$ directions is controlled by Oriental Motor $\alpha$-STEP stepper motors. The minimum step corresponds to movement of $0.4,0.1$, and $0.1 \mu \mathrm{m}$ in the $x, y$, and $z$ directions, respectively. The drivers are controlled by a LABVIEW program that runs on a PC via a National Instruments PCI-7314 open loop motion controller board. Limit and home switches are mounted on the manipulator and read by the LABVIEW motion control program. The repeatability of movement is estimated to be better than $0.01 \mathrm{~mm}$ in all directions.

The sample is mounted at the end of the manipulator arm (see Fig. 2), which shows the sample with an alignment tool. The end of the arm consists of a weldable feedthrough (TCK-30C, Caburn-MDC) with a $K$-type thermocouple and $30 \mathrm{~A} \mathrm{Cu}$ power connectors. The sample would typically be a metal single crystal with a diameter of $10-15 \mathrm{~mm}$ and height of $2-4 \mathrm{~mm}$. The sample is mounted on a $0.6 \mathrm{~mm}$ outer diameter (o.d.) $\mathrm{W}$ wire that passes through a pair of holes in the sample and is fastened to two $\mathrm{Cu}$ bars hanging from the power connectors; see Fig. 2. The W wire has a free length of about $15-25 \mathrm{~mm}$ in order to obtain sufficient resistive heating. The sample is supported from below by a support arm of copper, which is mounted on one of the sample holders and electrically insulated from it by a slice of mica. A short piece of $\mathrm{W}$ wire supported by a screw with a hole 
drilled in the end makes contact with the back side of the sample. This support is necessary to counteract the downward force on the sample exerted by the gas stream. The thermocouple is mounted in a hole in the side of the sample. The temperature is controlled by a Eurotherm 2408 temperature/process controller connected to a 0-125 A power supply.

The soldering used in the electrical feedtroughs on the end of the manipulator arm contains $\mathrm{Ni}$, which is catalytically active for some reactions and also forms volatile nickel carbonyls with $\mathrm{CO}$. In order to minimize the contact between the reaction gas in the high-pressure cell and the electrical feedthroughs at the end of the manipulator arm, a "shield" of machinable ceramic (Macor) is mounted over them before the sample holders are mounted. This also protects the feedthroughs from metal vapor during deposition of metals and sputtering.

It is very important that the sample surface is mounted so that it is parallel to the $x-y$ plane of gas sampling movement, as will be explained later. This is achieved by using a special alignment tool, shown in Fig. 2. The tool is the shape of a round aluminum disk the same size as the sample and is fixed relative to the flange of the ultrahigh vacuum lock. The sample is in the correct position when it is concentric with the alignment tool and the sample surface is just in contact with the lower, polished surface of the tool. When the highpressure cell is mounted, alignment of the sample surface can be checked by bringing the nose of the gas sampling device into ohmic contact with the sample surface. By using the method described above, it is possible to align the sample so that deviation in the height direction is less than $0.05 \mathrm{~mm}$ over a sample surface $10 \mathrm{~mm}$ in diameter.

\section{Ultrahigh vacuum lock for the high-pressure cell}

The design of the lock is inspired by a standard Conflat ultrahigh vacuum seal. Compared to a number of similar ultrahigh vacuum locks described in the literature, ${ }^{15}$ it has the advantage of being all metal sealed and He leak tight when closed. Thus the ultrahigh vacuum chamber will remain at a pressure in the low $10^{-10}$ Torr range when the high-pressure cell is filled with gas at atmospheric pressure.

The ultrahigh vacuum lock is shown in Fig. 3. The lock is mounted on a $2.75 \mathrm{in}$. gate valve (not shown). After opening the valve, the sample is moved into the high-pressure cell. When the sample is close to its correct position in the high-pressure cell, a knife edge on the manipulator head seals it against a $\mathrm{Cu}$ gasket. A guide steers the manipulator head to the correct position. The manipulator head is then locked with a fork on the ultrahigh vacuum side of the seal. The $\mathrm{Cu}$ gasket is pressed against the knife edge on the manipulator head by tightening the locking bolt.

As shown in Fig. 3, the high-pressure cell is mounted on the exterior side of the double flange of the ultrahigh vacuum lock. When the manipulator head is locked, the high-pressure cell can be removed to allow the sample to be exchanged. The high-pressure cell can then be mounted and pumped down separately with the $70 \mathrm{l} / \mathrm{s}$ turbo pump. The highpressure cell thus also works as a load lock.

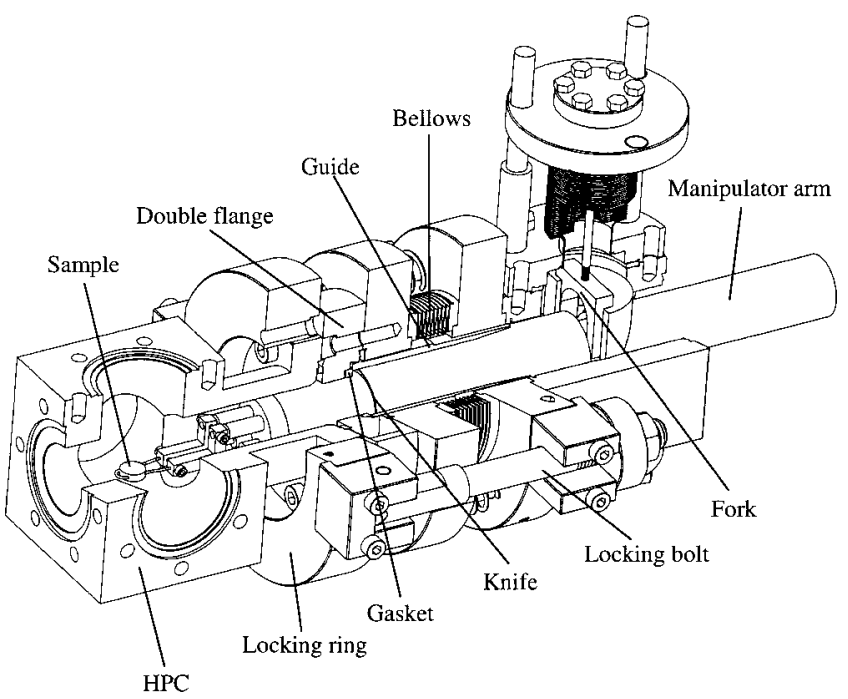

FIG. 3. Ultrahigh vacuum lock with the high-pressure cell mounted. Shown is a situation where the sample has reached the measurement position in the high-pressure cell. The manipulator arm is kept in place by the fork. When the nut on the locking bolt is tightened, the locking ring will press on the double flange carrying the high-pressure cell. The gasket sits on the inside of the double flange and is then pressed against the knife edge on the manipulator arm. The gasket is held in place by the conical guide, which also steers the manipulator head toward the correct sealing position during sample transfer. The bellows take up motion of the double flange when the locking bolt is tightened. The sample hangs from two copper rods, which are mounted on the power feedthroughs at the end of the manipulator. The support under the sample and the thermocouple wires are not shown.

\section{High-pressure cell}

The high-pressure cell has five CF70 flange connections. It is mounted on the high-pressure lock and the gas sampling stage is mounted on top of it, as shown in Fig. 4. The highpressure cell is manufactured of Ni-free steel (ARNE steel, W no. 1.2510), in order to minimize the formation of nickel carbonyls during experiments with CO. Unfortunately, it is not possible to weld this kind of steel. Hence the manipulator arm and the window flanges are made of 316 stainless steel, which contains Ni.

During initial testing of the system, two windows were mounted on the high-pressure cell to facilitate sample transfer and positioning of the sampling device. Also, the edgewelded bellows that are part of the gas sampling device are of the type to be used with vacuum on the inside. This limits the pressure in the high-pressure cell to 1 bar. Without the windows, and with edge-welded bellows made to be used with overpressure inside, it should be possible to run experiments at pressures up to at least 5 bar.

The sample can be heated to at least $500{ }^{\circ} \mathrm{C}$ with $1 \mathrm{~atm}$ pressure in the high-pressure cell. The limit is set by the current limit of the electrical feedthroughs. At this temperature the glass windows in the high-pressure cell do not get hot. With pure $\mathrm{H}_{2}$ or $\mathrm{He}$ the maximum temperature achievable is about $350{ }^{\circ} \mathrm{C}$ due to the higher thermal conductivity of those gases.

\section{E. Gas sampling}

An obvious requirement is that it should be possible to measure the catalytic activity for each spot individually. This 


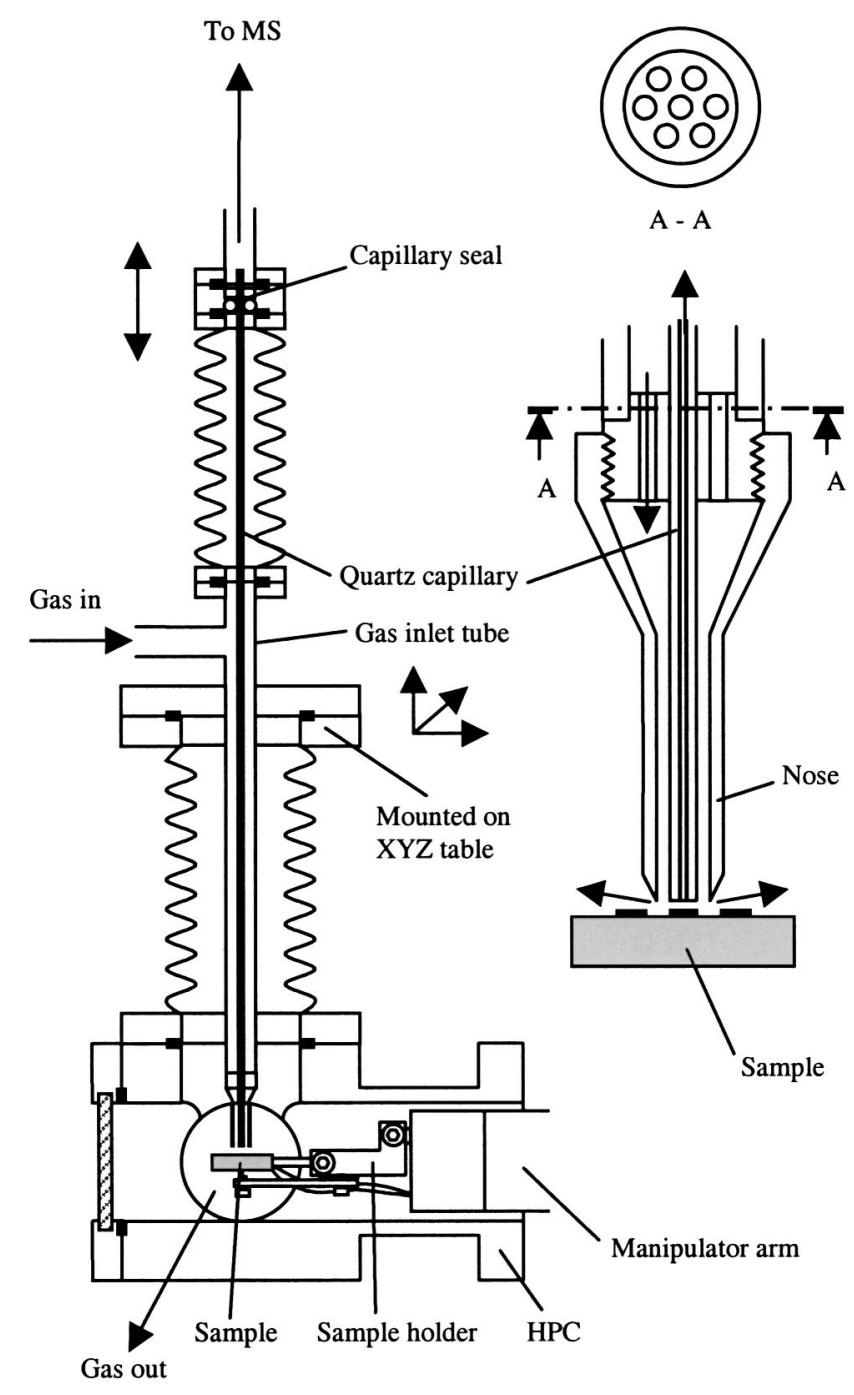

FIG. 4. Principles of the high-pressure experiment. The flange where the quartz capillary is sealed is attached to a linear manipulator which is mounted on the $X Y Z$ table. Movement is taken up by edge-welded stainless steel bellows. Two of the side flanges on the high-pressure cell are used for windows, and the third for the gas outlet. Also shown is an enlargement of the lower part of the gas inlet tube with the quartz capillary and the nose.

is achieved by sampling the gas close to the sample surface and by minimizing the diffusion of reaction products from adjacent spots toward the sampling device.

Gas sampling is made with a quartz capillary of the type invented by Kasemo. ${ }^{14}$ This gives the advantage of very small gas flow through the sampling device [about $\left.0.02(\mathrm{ml} / \mathrm{min})_{n}\right]$ and, thus, spatial resolution better than 0.5 $\mathrm{mm}$ in the gas phase. ${ }^{16}$

The sampling device consists of a concentric arrangement of a $6 \mathrm{~mm}$ o.d. stainless steel tube with the quartz tube in the center; see Fig. 4. Gas is blown toward the sample surface through the steel tube. The gas flow resembles stagnation flow, leaving a point of stagnation on the surface under the quartz capillary leak. The gas that passes outward from under the nose will counteract diffusion of the species formed on neighboring spots toward the capillary.

The quartz capillary is sealed at the top of the gas inlet tube at its $2 \mathrm{~mm}$ o.d. end with a $3.56 \times 0.76 \mathrm{~mm}$ Betech Seals flourine rubber $\mathrm{O}$ ring, which is made with sulfur-free $\mathrm{TiO}_{2}$ filling. The capillary seal is machined from a doublethickness CF 40 flange. A small cylinder and a screw with a $2 \mathrm{~mm}$ center hole are passed over the capillary and the seal is made by forcing the cylinder down onto the $\mathrm{O}$ ring by turning the screw in a thread cut into the flange. The presence of the small cylinder was found to improve the seal significantly.

The quartz capillary is made of a $50 \mathrm{~mm}$ long piece of $0.9 \mathrm{~mm}$ o.d. quartz tubing $( \pm 10 \%$ tolerance, Quartz Plus, Inc.) which is joined to a $2 \mathrm{~mm}$ o.d. quartz tube by melting in a hydrogen-oxygen flame. (The $1 \mathrm{~mm}$ o.d. tube is too fragile to be sealed by an $\mathrm{O}$ ring.) The leak at the end of the $0.9 \mathrm{~mm}$ o.d. capillary is made by pumping the capillary with a turbo pump and monitoring the pressure while heating the quartz with a hydrogen flame. ${ }^{14}$

At the lower end, the capillary is stabilized by passing it through the center hole of a $6 \mathrm{~mm}$ o.d. stainless steel disk welded into the bottom of the $6 \mathrm{~mm}$ steel tube; see Fig. 4 . The gas flows through six $1 \mathrm{~mm}$ diam holes that surround the hole for the capillary.

The gas is directed onto the sample surface through an aluminum sampling nose screwed onto the end of the gas inlet tube. Aluminum was chosen as the material for the nose because of its chemical inertness for the chemical reactions of interest here. The nose can easily be exchanged for one made from another material, or one with another shape, if necessary.

The capillary can be moved up and down with respect to the gas inlet tube by turning a micrometer screw that drives linear motion. It is important to be able to position the capillary accurately, since the gas composition may vary rapidly with distance from the sample, as will be shown later.

The gas inlet tube is welded into a CF 70 flange, which is mounted on a single bellows $x y z$ manipulator which, in turn, is mounted on the high-pressure cell; see Fig. 4. In this way the entire gas sampling device can be moved in three dimensions above a sample locked in the high-pressure cell.

Motion of the $x y z$ table is controlled by three Oriental Motor $\alpha$-STEP stepper motors in the same way as for the main manipulator. The minimum step in motion is $0.1 \mu \mathrm{m}$ in all three dimensions. Motion of the gas sampling device is controlled by a LABVIEW program which also communicates with the mass spectrometer. Measurements can be programmed in advance and then be carried out automatically.

\section{F. Gas analysis}

The gas sampled by the quartz capillary is led to a small ultrahigh vacuum chamber pumped by a $250 \mathrm{l} / \mathrm{s}$ turbo pump which contains the mass spectrometer. The leak of the quartz capillary is made to yield pressure in the mass spectrometer chamber of about $2 \times 10^{-6}$ Torr with pressure of 1 bar in the high-pressure cell.

The mass spectrometer is a Balzers QMA 125 quadrupole mass spectrometer with an axial ion source. The detector used is either a Faraday cup or an off-axis SEM. Control electronics for the mass spectrometer are controlled by a LABVIEW program running on a PC. 


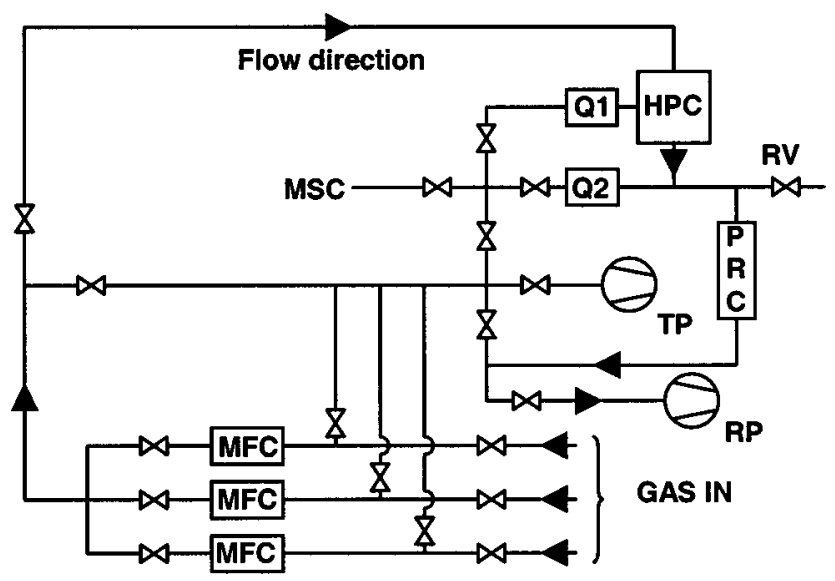

FIG. 5. Gas handling system. MFC are mass flow controllers $0-20(\mathrm{ml} / \mathrm{min})_{n}$, HPC the high-pressure cell, Q1 is the quartz capillary mounted in the gas sampling device, and Q2 the quartz capillary leak mounted on the gas outlet from the HPC. PRC denotes pressure controller. MSC is the mass spectrometer chamber, TP the $701 / \mathrm{s}$ turbo pump, and RP the roughing pump. $\mathrm{RV}$ is the relief valve.

A number of valves mounted on the mass spectrometer chamber make it possible to switch between the main capillary and the capillary mounted on the outlet of the highpressure cell. The gas lines which connect the quartz capillary leaks with the mass spectrometer chamber can be evacuated by the same pumps used to evacuate the gas handling system.

\section{G. Gas handling system}

The gas handling system can deliver a mixture of three different gases [at $0-20(\mathrm{ml} / \mathrm{min})_{n}$ each] to the highpressure cell at pressure of $0.25-5$ bar; see Fig. 5. The gas lines consist of electropolished stainless steel tubes and $\mathrm{Nu}-$ pro all-metal bellows-sealed valves. The system can be evacuated by a roughing pump and a 70 1/s turbo pump.

The flow of gases is regulated by three Brooks Instruments 5964 ultraclean metal seal mass flow controllers on the inlet side. When using $\mathrm{CO}$, one of the mass flow controllers is exchanged for a Brooks Instruments 5850S/BC, which does not expose Ni to the gas stream. (The 5964 version is sealed with Ni gaskets.)

On the exit line of the high-pressure cell, a pressure relief valve is mounted together with a Brooks Instruments 5866 pressure controller. The downstream pressure of the controller during a high-pressure experiment is maintained at, typically, $5 \times 10^{-2}$ Torr by the roughing pump.

The mass flow controllers, as well as the pressure controller, are connected to a control and read-out unit that can be operated from the PC.

Gases delivered to the system are $\mathrm{N} 60(99.9999 \%) \mathrm{H}_{2}$, Ar, $\mathrm{He}, \mathrm{O}_{2}, \mathrm{~N} 48(99.998 \%) \mathrm{CO}$, and $99.8 \% \mathrm{D}_{2}$ (main contaminant $\mathrm{H}_{2}$ ). The $\mathrm{CO}$ stream is filtered first by an active carbon filter and then by a Waferpure mini-xl CO purifier for removal of nickel carbonyls. The Ar gas was cleaned by passing it over a Fe catalyst reduced in hydrogen at $450{ }^{\circ} \mathrm{C}$.

The gas mixture enters the high-pressure cell through the sampling device and exits through a tube on the side of the high-pressure cell.

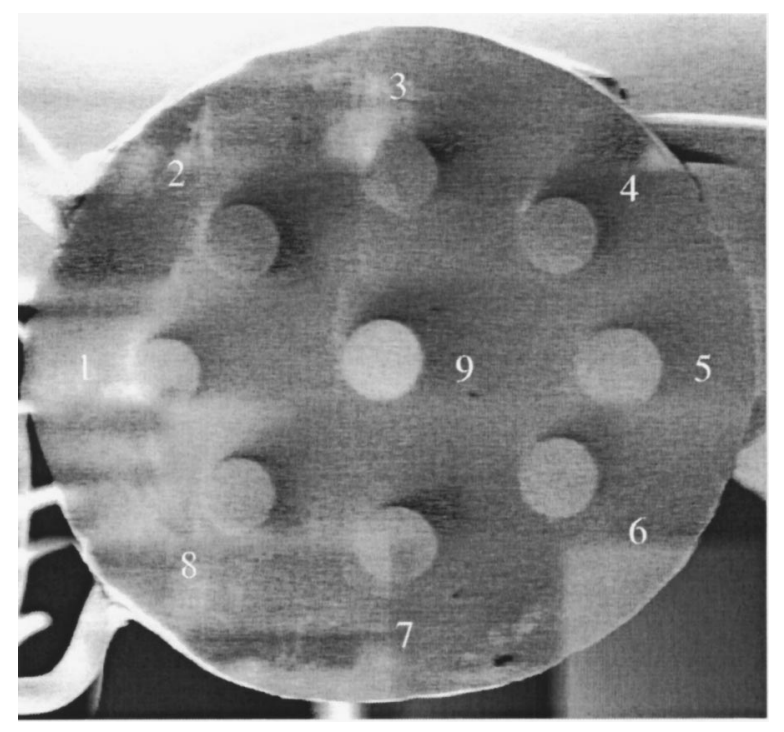

FIG. 6. Secondary electron microscope image of an oxidized Al(111) crystal with nine spots evaporated onto it. The spots have a diameter of $1 \mathrm{~mm}$ and the crystal has a diameter of $10 \mathrm{~mm}$. Spots 1 and 5 consist of $500 \AA \mathrm{Pd}$, spots 2 and 8 of $250 \AA \mathrm{Pd}$, spots 3 and 7 of $1000 \AA$ Pd and spots 4 and 6 of $125 \AA$ Pd. Spot 9 consists of $1000 \AA$ Au. The image was put together from 25 smaller parts, each about $2 \times 2 \mathrm{~mm}$. The electron beam had energy of 1.1 $\mathrm{kV}$.

\section{EXPERIENCE GAINED FROM OPERATING THE APPARATUS}

A typical measurement cycle starts with mounting and aligning the sample, described above. The high-pressure cell is then mounted, pumped down, and baked. The sample is prepared for metal deposition by sputtering, annealing, and, if necessary, oxidation in the high-pressure cell. When the model catalysts are manufactured, they are usually studied with AES or XPS before the sample is moved to the highpressure cell. Such measurements are useful references, since the catalysts might undergo dramatic changes, e.g., contamination, segregation, or restructuring during exposure to gases at atmospheric pressure at elevated temperatures. After measurements in the high-pressure cell, the catalysts can be studied with the whole range of surface analysis tools available. The last step would usually be sputter profiling of some of the more interesting spots. A complete measurement cycle typically takes a week to perform. The most time-consuming steps are sample manufacturing and surface analysis. The cycle time can thus be decreased if surface analysis is only carried out on those samples which gave the most interesting results in the high-pressure experiment. It is important to carry out surface analysis (AES, ISS, XPS) also on one of the least active spots to rule out contamination as a reason for inactivity.

Figure 6 shows a SEM image of nine spots with diameters of $1 \mathrm{~mm}$ made by electron-beam deposition on an oxidized $\mathrm{Al}(111)$ crystal. The thickness of the spots varies between 100 and $1000 \AA$, as measured with the quartz crystal microbalance. The spots are clearly visible in SEM and, as can be seen in Fig. 6, their shape is quite circular. The edges of the spots are quite sharp. From SEM images with higher magnification and from Auger maps, the resolution of the deposition process seems to be of the order of $0.01 \mathrm{~mm}$. So 

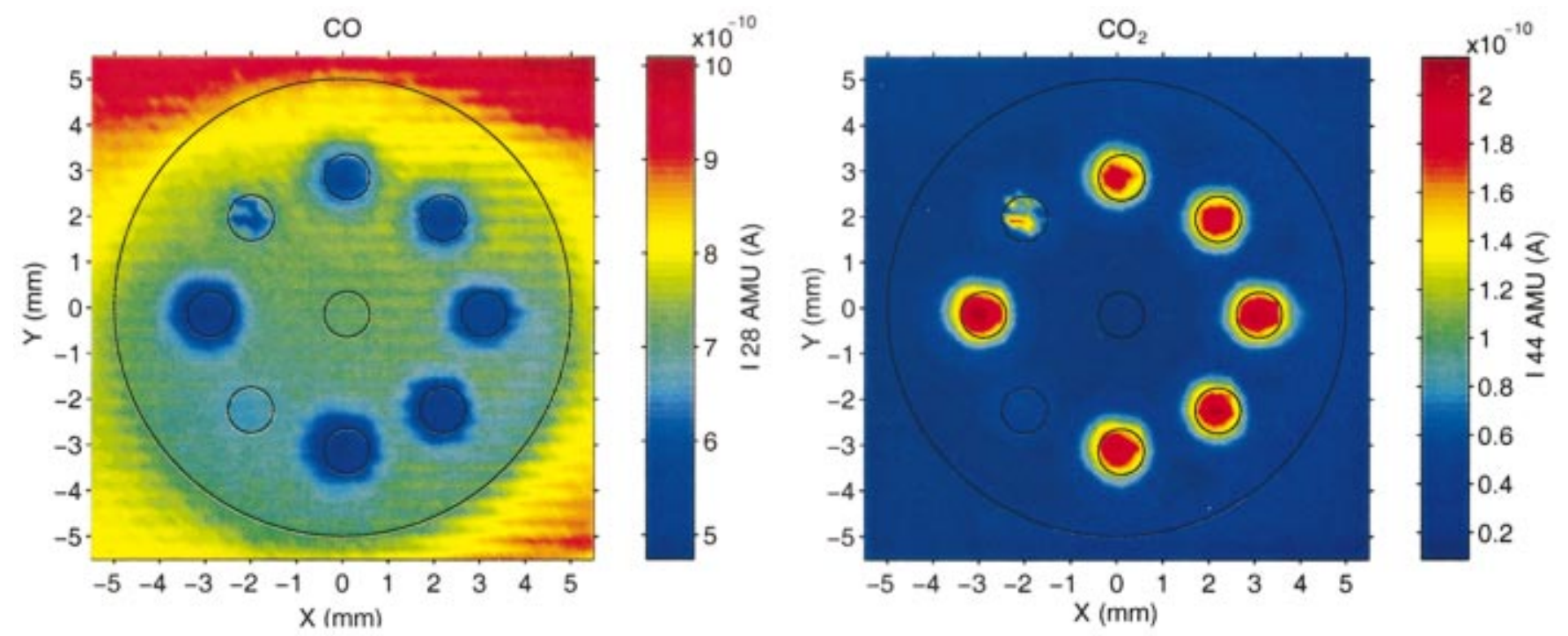

FIG. 7. (Color) $\mathrm{CO}$ and $\mathrm{CO}_{2}$ mass spectrometer signals measured over an oxidized $\mathrm{Al}(111)$ crystal with eight Pd spots surrounding one Au spot. The positions of the spots and the periphery of the $\mathrm{Al}$ crystal are indicated. The measurement was made at $300{ }^{\circ} \mathrm{C}$ with $1.3 \% \mathrm{CO}$ and $6.6 \% \mathrm{O}_{2}$ in $\mathrm{Ar}$ at total pressure of 1 bar and gas flow of $30.4(\mathrm{ml} / \mathrm{min})_{n}$. If the spots are numbered the same as in Fig. 6 , spots 1 and 5 consist of $250 \AA$ Pd, spots 2 and 8 of $62 \AA$ Pd, spots 3 and 7 of $500 \AA$ Pd, and spots 4 and 6 of $125 \AA$ Pd. Spot 9 consists of $500 \AA$ Au. The distance between the nose and the sample surface was $0.2 \mathrm{~mm}$ and the tip of the quartz capillary was positioned $0.05 \mathrm{~mm}$ inside the nose (see Fig. 4). The nose was scanned over the surface in $0.2 \mathrm{~mm}$ steps. The delay time was $30 \mathrm{~s}$. The signals measured every $0.2 \mathrm{~mm}$ were interpolated and color coded to produce the maps.

far, the studies have been limited to $\mathrm{Pd}, \mathrm{Ni}, \mathrm{Cu}, \mathrm{Ag}$, and $\mathrm{Au}$. The maximum practical evaporation rate for these metals is about $50 \AA$ Amin with this equipment. Due to problems with the stability of the electronics of the evaporator, it has so far been operated manually. Since manufacturing of 20 spots with various metal compositions takes several hours, also at the maximum evaporation rate, it would be highly desirable to program the compositions in advance and run the evaporator automatically.

Figure 7 shows the result of a $\mathrm{CO}$ oxidation highpressure experiment made with a sample similar to that shown in Fig. 6. There are eight Pd spots of varying thickness surrounding one Au spot at the center of the sample.

The substrate used in the experiment was an $\mathrm{Al}(111)$ crystal which was sputtered clean and then annealed at $500{ }^{\circ} \mathrm{C}$ for $1 \mathrm{~h}$. Before metal deposition the sample was oxidized by exposure in the high-pressure cell to a mixture of $6.6 \% \mathrm{O}_{2}$ and $1.3 \% \mathrm{H}_{2}$ in $\mathrm{Ar}$ at total pressure of 1 bar at $250{ }^{\circ} \mathrm{C}$ for $1.5 \mathrm{~h}$.

The increase in the $\mathrm{CO}_{2}$ signal $(44 \mathrm{amu})$ over the $\mathrm{Pd}$ spots is caused by the production of $\mathrm{CO}_{2}$ from $\mathrm{CO}$ and $\mathrm{O}_{2}$. The $\mathrm{Au}$ spot and the aluminum oxide surface are obviously not active as catalysts for $\mathrm{CO}$ oxidation. The mass spectrometer signal corresponding to $\mathrm{CO}(28 \mathrm{amu})$ shows a decrease over the Pd spots. This is because $\mathrm{CO}$ is consumed in the reaction, which leads to depletion of $\mathrm{CO}$ close to the $\mathrm{Pd}$ surface as a consequence of mass transport limitations. The increase in the $\mathrm{CO}_{2}$ signal over the Pd spots correlates well with the decrease in $\mathrm{CO}$ signal.

Prior to this experiment, the sample had been used in a number of other experiments and it had also been sputtered several times. Spot Nos. 2 and 8 (the thinnest ones) have therefore been partially removed from the surface. The signal obtained from the remaining parts of these spots shows that it is possible to resolve features as small as $0.2 \mathrm{~mm}$ with this technique. Figure 7 also shows that the peaks in the product $\left(\mathrm{CO}_{2}\right)$ signal do not extend more than $0.5 \mathrm{~mm}$ outside the $\mathrm{Pd}$ spots. The minimum distance between two adjacent spots in order to avoid crosstalk would thus be $1 \mathrm{~mm}$ in this experiment.

When scanning the gas sampling device over the sample surface, the mass spectrometer chamber must be given time to achieve steady state. This will limit the rate at which the surface can be scanned. For $\mathrm{H}_{2}$, a delay of $10 \mathrm{~s}$ is enough, for $\mathrm{CO}$ the delay must be about $20 \mathrm{~s}$ while for water $5 \mathrm{~min}$ is the minimum. The longer time necessary for $\mathrm{CO}$ and water is mainly due to adsorption of these gases on the walls in the mass spectrometer chamber and in the gas lines connecting the mass spectrometer chamber to the capillary (length about $1 \mathrm{~m})$. A measurement with $56 \times 56$ points like the one shown in Fig. 7 thus takes about $18 \mathrm{~h}$ to perform. When testing the catalytic activity of an array of spots it is only necessary to measure at one point over each spot. A measurement can thus be performed in a few minutes once the right conditions have been established in the high-pressure cell.

The mass spectrometer signal obtained for a gas $n, I_{n}$, does not only depend on the partial pressure of the gas, $p_{n}$, but is also dependent on the local absolute temperature at the tip of the quartz capillary, $T$,

$$
I_{n}=\chi_{n} \frac{p_{n}}{T^{\alpha}}
$$

where $\chi_{n}$ is a calibration factor. ${ }^{16} \alpha$ varies somewhat between capillaries and the exact value has to be found by calibration measurement. Usually $\alpha \approx 1$. (For simplicity it is assumed here that only one gas contributes to the mass spectrometer signal.)

This means that variations in the gas temperature will affect measurements. Since only the sample, not the sur- 


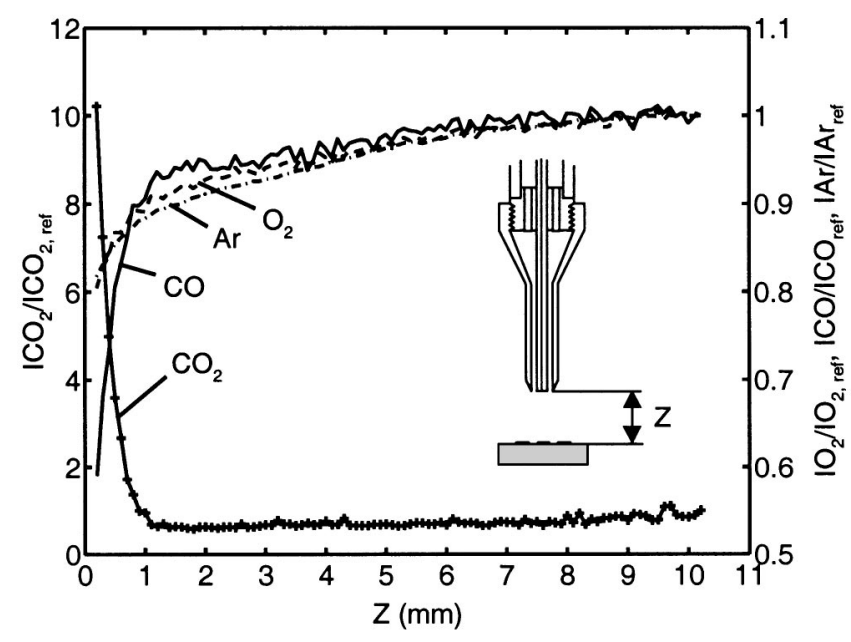

FIG. 8. Mass spectrometer signals as a function of the distance between the sample surface and the nose. The experiment was made at $300{ }^{\circ} \mathrm{C}$ with $1.3 \%$ $\mathrm{CO}$ and $6.6 \% \mathrm{O}_{2}$ in $\mathrm{Ar}$ at total pressure of 1 bar and gas flow of $30.4(\mathrm{ml} / \mathrm{min})_{n}$. The mass spectrometer signals were normalized to the value obtained $10 \mathrm{~mm}$ from the surface. The tip of the capillary was positioned $0.05 \mathrm{~mm}$ inside the nose.

rounding gas, is heated in these experiments there will be temperature gradients in the gas surrounding the sample. The increase in the $\mathrm{CO}$ signal when the nose is positioned outside the substrate, which can be seen in Fig. 7, is thus due to a lower gas temperature outside the edge of the substrate.

Provided that the partial pressure of the carrier gas, $p_{c}$, can be considered constant throughout the high-pressure cell, the mass spectrometer signal for the carrier gas, $I_{c}$, can be used to compensate for the influence of the gas temperature. From Eq. (1) it follows

$$
p_{n}=\frac{\chi_{c} p_{c}}{\chi_{n}} \frac{I_{n}}{I_{c}} \text {. }
$$

The $\mathrm{O}_{2}$ and Ar signals were also measured in the experiment shown in Fig. 7, but the variations in these signals over the interior of the sample surface were within the noise level. This indicates that temperature variations over the interior of the sample surface were small. (A large amount of excess oxygen was present in this experiment and the oxygen pressure was thus not lowered significantly as an effect of mass transport limitations.)

The gas composition measured at the tip of the quartz capillary may vary rapidly when the gas sampling device is retracted from the catalytic surface, as shown in Fig. 8. This means that deviation of a tenth of a $\mathrm{mm}$ in the alignment of the sample to the plane of motion of the gas sampling device will give rise to a large difference in observed catalytic activity for two spots with the same activity. To safeguard against this, the spots are placed so that two spots with identical thickness and composition are placed at different positions on the substrate.

What is shown in Fig. 8 is actually the mass spectrometer signals relative to the mass spectrometer signals at the maximum distance from the sample surface $(\sim 10 \mathrm{~mm})$. In this case, with low conversion of the gas mixture, the reactant signal values at the maximum distance more or less equal the values obtained for the homogeneous gas let into

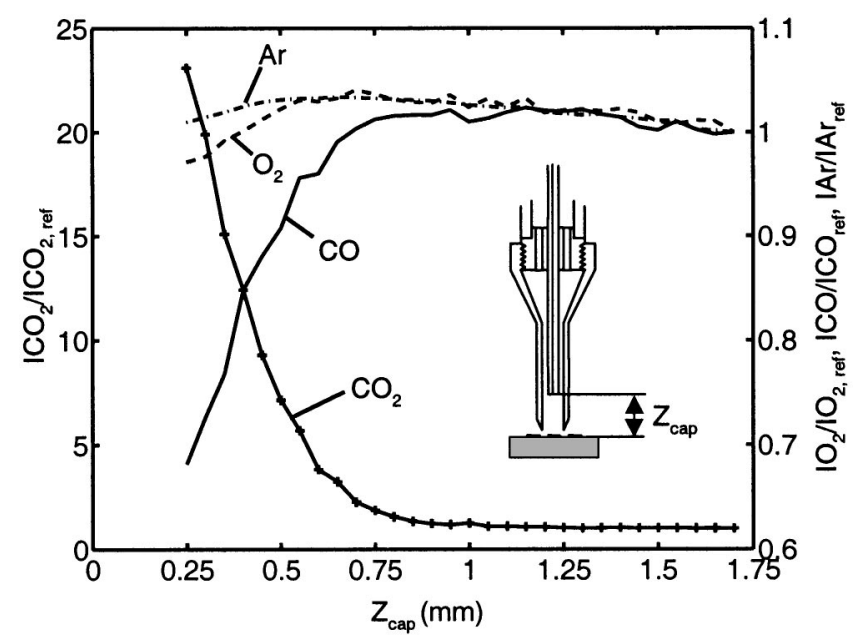

FIG. 9. Mass spectrometer signals as a function of the distance from the sample surface to the tip of the quartz capillary. The tip of the capillary is retracted from a position $0.05 \mathrm{~mm}$ inside the nose, while the nose is kept fixed $0.2 \mathrm{~mm}$ from the surface. The experiment was made at $300{ }^{\circ} \mathrm{C}$ with $1.3 \% \mathrm{CO}$ and $6.6 \% \mathrm{O}_{2}$ in $\mathrm{Ar}$ at total pressure of 1 bar and gas flow of $30.4(\mathrm{ml} / \mathrm{min})_{n}$. The mass spectrometer signals were normalized to the value $1.7 \mathrm{~mm}$ from the surface.

the reactor. (This was checked by moving the tip of the capillary inside the nose, discussed below.) The signal value at the maximum distance for $\mathrm{CO}_{2}$ more or less corresponds to the concentration of $\mathrm{CO}_{2}$ in the reactor. This is because backdiffusion is not prevented when the distance between the nose and the sample surface becomes large.

The variation in Ar signal is mainly caused by the decrease in the gas temperature when the nose is retracted from the heated surface. It would be possible to use Eq. (2) to calculate the partial pressures from the mass spectrometer signals, but it is clear anyhow that the $\mathrm{CO}$ pressure increases and the $\mathrm{CO}_{2}$ pressure decreases in the first $6 \mathrm{~mm}$ of movement out from the sample surface.

The position of the tip of the capillary is also important. By moving the quartz capillary relative to the gas inlet tube, the gas composition can be studied as a function of the distance from the sample surface, at least if the influence of the position of the quartz tube on the gas flow is neglected; see Fig. 9.

Already $1 \mathrm{~mm}$ from the end of the nose the gas is homogeneous. This means that the partial pressures of the reactants are equal to those in the gas fed to the reactor. By retracting the capillary to this position it is thus possible to calibrate the mass spectrometer signals to the known composition of the gas fed to the reactor and, thus, to obtain quantitative data for the partial pressures of the reactants close to the catalytic surface. By comparing such data to computational fluid dynamics simulations it is possible to obtain the reaction rate as a function of the partial pressures of reactants and products at the catalytic surface. ${ }^{17}$

The broad maximum in the $\mathrm{O}_{2}$ and Ar signals at $Z_{\text {cap }}$ $=0.6 \mathrm{~mm}$ may be due to variation in the total pressure and/or temperature when the quartz tube is moved inside the nose.

As can be seen from Fig. 9 the partial pressures of the reactants at the catalytic surface are significantly lower than the pressures in the incoming gas. 


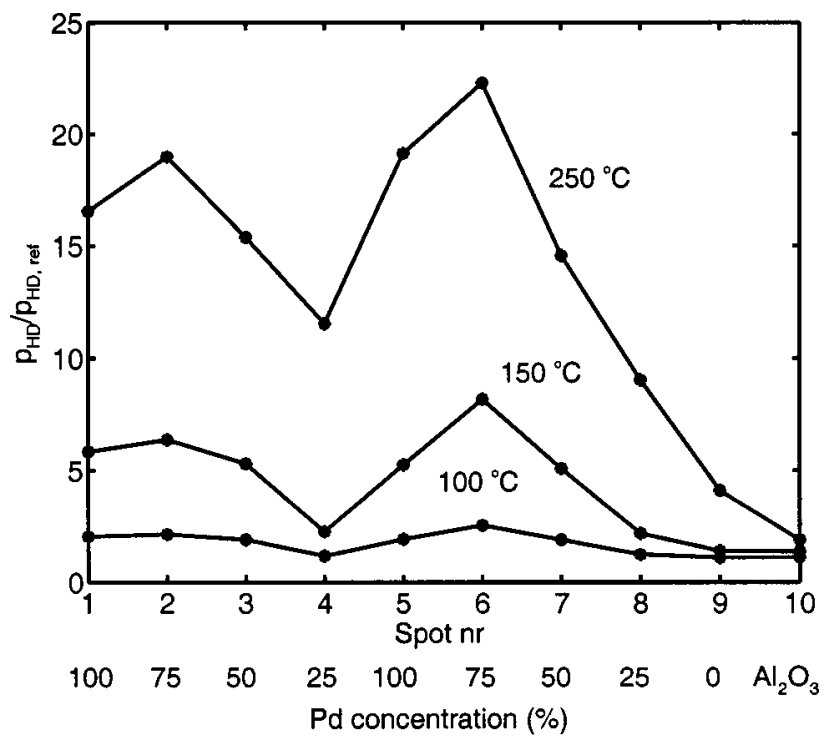

FIG. 10. HD pressure relative to the background HD pressure over the centers of coevaporated $\mathrm{Pd} / \mathrm{Ni}$ spots. Spot 10 is a position on the aluminum oxide support, well away from the metal spots. The ion currents measured for $3 \mathrm{amu}$ were divided by the value obtained at $20 \mathrm{amu}$. The value for spot 10 obtained at $80^{\circ} \mathrm{C}$ is used as the background value. The measurement was made with total gas flow of $57.6(\mathrm{ml} / \mathrm{min})_{n}$ that consisted of $1.4 \% \mathrm{H}_{2}$ and $1.4 \% \mathrm{D}_{2}$ in Ar at total pressure of 1 bar. The distance between the nose and the sample surface was $0.2 \mathrm{~mm}$ and the tip of the quartz capillary was positioned $0.05 \mathrm{~mm}$ inside the nose; see Fig. 4.

The measurement becomes more sensitive to the products as the tip of the capillary is moved closer to the catalytic surface. It is, however, advantageous to position the capillary tip inside the nose, so that it is protected from accidental contact with the sample surface.

\section{EXAMPLES OF EXPERIMENTAL RESULTS}

As an example of the kind of measurements that can be performed with this apparatus, an experiment is shown where the rate of the $\mathrm{H}_{2}-\mathrm{D}_{2}$ exchange reaction was studied as a function of the $\mathrm{Pd}-\mathrm{Ni}$ composition on an oxidized aluminum substrate. This reaction is of interest in connection with fuel cells where dissociation of $\mathrm{H}_{2}$ on the commonly used $\mathrm{Pt}$ anode is poisoned by ppm levels of $\mathrm{CO}^{18}$ The rate of the $\mathrm{H}_{2}-\mathrm{D}_{2}$ exchange reaction is used as a measure of the capability of the metal alloy to split $\mathrm{H}_{2}$. The ultimate objective would be to find an alloy which dissociates $\mathrm{H}_{2}$ effectively also in presence of $\mathrm{CO}$ and water.

A $99.99999 \%$ pure, polycrystalline aluminum sample, 10 $\mathrm{mm}$ in diameter and about $2 \mathrm{~mm}$ thick, was sputtered clean, annealed at $500^{\circ} \mathrm{C}$ for $1 \mathrm{~h}$, and then oxidized in the highpressure cell by exposure to $20 \% \mathrm{O}_{2}$ in $\mathrm{Ar}$ at total pressure of $1 \mathrm{bar}$ at a temperature of $400^{\circ} \mathrm{C}$ for $21 \mathrm{~h}$. It was then taken back into the ultrahigh vacuum chamber for metal deposition. The $\mathrm{Ni}$ and $\mathrm{Pd}$ were codeposited from aluminum oxide crucibles at a rate of $10 \AA / \mathrm{min}$. The diameter of the spots was $1 \mathrm{~mm}$ and their total thickness was $100 \AA$ A. The composition of the spots varied from pure Pd to pure Ni. Numbering of the spots on the sample surface was made clockwise from the periphery inward, as shown in Fig. 6.

After the spots were characterized with AES, the sample was moved to the high-pressure cell and exposed to a gas

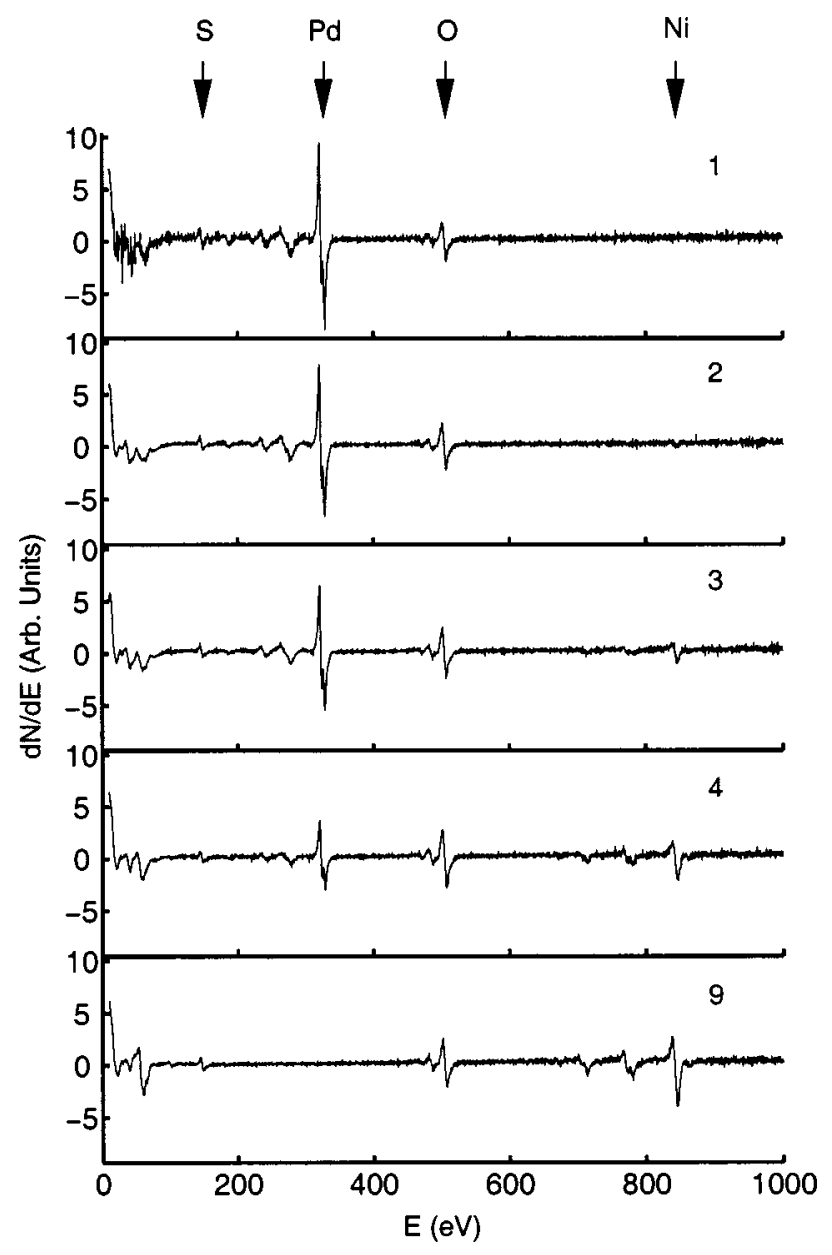

FIG. 11. AES spectra of spots $1-4$ and 9 obtained after the high-pressure experiments. The measurements were performed at the center of each spot with beam energy of $3 \mathrm{kV}$.

mixture of $1.4 \% \mathrm{H}_{2}$ and $1.4 \% \mathrm{D}_{2}$ in Ar at total pressure of 1 bar. The HD production was measured over the center of each spot. The tip of the capillary was positioned at the end of the nose and the distance between the end of the nose and the sample surface was $0.2 \mathrm{~mm}$. The result of a number of such measurements at different temperatures is shown in Fig. 10.

The partial pressure of HD in Fig. 10 is given relative to the HD pressure at $80^{\circ} \mathrm{C}$ at a position on the aluminum oxide surface well away from the metal spots. At $80^{\circ} \mathrm{C}$ the activity for HD production is very low, even on the metal spots, and this value thus corresponds to the background level caused by HD production in the ion source of the mass spectrometer and HD present in the incoming gas. In order to compare the HD pressures measured at different temperatures, the ion current for $3 \mathrm{amu}$ was divided by the ion current for $20 \mathrm{amu}$; see Eq. (2). It is a good approximation to assume that the $\mathrm{Ar}$ pressure is constant in this case since the physical properties of the gas mixture do not change significantly as a result of the chemical reaction. (If, e.g., the mole number had changed in the reaction the Ar pressure would not have been constant.) As judged from the Ar mass spectrometer signal, the temperature at a fixed distance from the surface was nearly constant over the interior of the sample surface where the spots are located; see Eq. (1). 


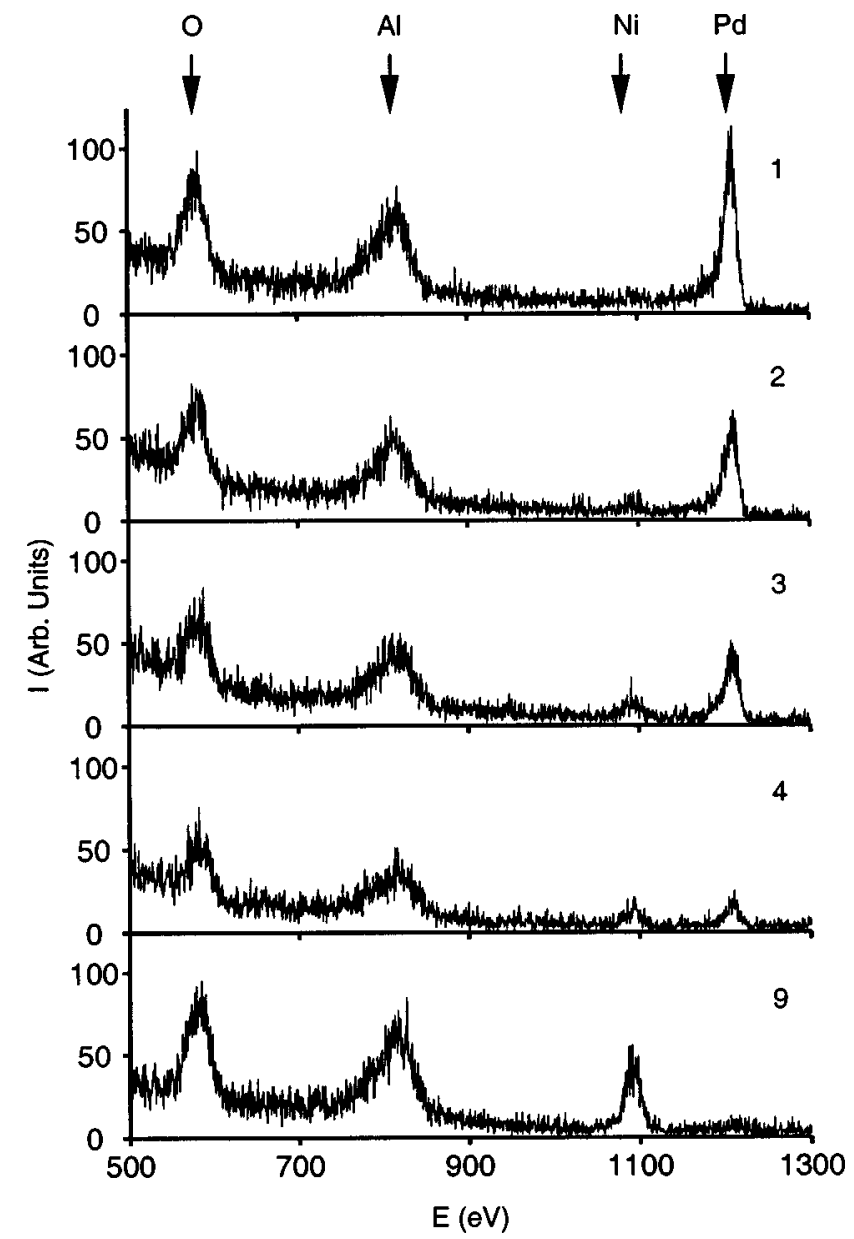

FIG. 12. ISS spectra of spots $1-4$ and 9 obtained after the high-pressure experiments. The primary energy of the $\mathrm{He}$ ions used was $1250 \mathrm{eV}$. The angle between the ion gun and the analyzer is $130^{\circ}$.

As can be seen from Fig. 10, the spots with $25 \% \mathrm{Ni}$ in $\mathrm{Pd}$ are more active for $\mathrm{H}_{2}-\mathrm{D}_{2}$ exchange than pure $\mathrm{Pd}$. Before the measurements shown here, the sample had been run continuously in the same gas mixture for $48 \mathrm{~h}$ at temperatures between 80 and $250{ }^{\circ} \mathrm{C}$. The activity at $150{ }^{\circ} \mathrm{C}$ decreased by a factor of 2 during the first $24 \mathrm{~h}$ for all the metal spots, whereas the activity at 100 and $250{ }^{\circ} \mathrm{C}$ was unchanged. After the first $24 \mathrm{~h}$ no change in activity over time could be detected. The differences in activity between the two series of spots are probably due to small tilt of the sample. The high $x$ end was about $0.1 \mathrm{~mm}$ higher than the low $x$ end; see Fig. 6. A small difference in composition due to fluctuations in the metal flux rates during sample manufacturing cannot be ruled out either. The composition values obtained from AES vary by \pm 5 in units between the two series. This is within the accuracy of the quantitative AES analysis.

After the high-pressure experiments were carried out, the spots were studied with AES and ISS. Figure 11 shows AES spectra for spots 1-4 and 9. The Pd peak decreases and the $\mathrm{Ni}$ peak increases in accordance with the expected bulk composition. Oxygen is present in all spectra. Oxygen was present in roughly the same amount also in the AES spectra obtained before the high-pressure experiment. One explanation for this could be that the $100 \AA$ thick metal spots have cracks which reveal the aluminum oxide. No cracks could,

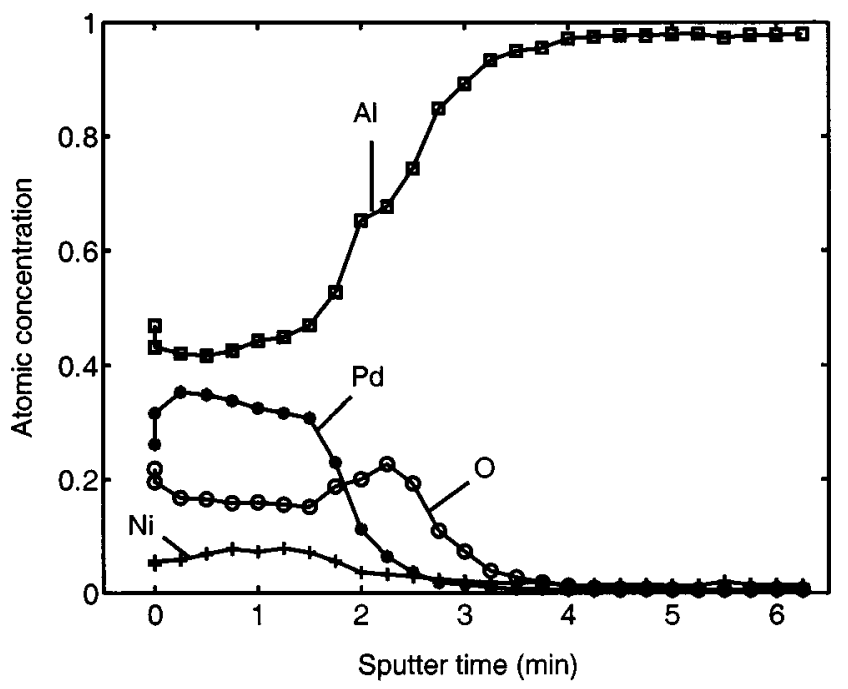

FIG. 13. Sputter profile obtained for spot $2(25 \% \mathrm{Ni}, 75 \% \mathrm{Pd})$. Surface analysis was carried out with AES with beam energy of $5 \mathrm{kV}$. Sputtering was done with $\mathrm{Ar}$ ions with energy of $4 \mathrm{kV}$ at ion flux of approximately 0.55 $\mathrm{A} / \mathrm{m}^{2}$. The atomic concentrations were calculated from peak to peak values obtained from differentiated spectra. The sensitivity factors used were taken from Ref. 19. The values used are for $\mathrm{Al}(1396 \mathrm{eV}) 0.075, \mathrm{Ni}(848 \mathrm{eV})$ 0.255, O (503 eV) 0.43, and Pd (330 eV) 0.9.

however, be detected with SEM. There is also sulfur in all the spectra. The spectra obtained before the high-pressure measurement did not show detectable levels of sulfur. The sulfur contamination is probably the result of a minute amount of sulfur being present in the gas in the high-pressure cell.

Figure 12 shows ISS spectra obtained with $1250 \mathrm{eV} \mathrm{He}$ ions. Qualitatively, if the areas of the $\mathrm{Pd}$ and Ni peaks are compared, it seems that the $\mathrm{Pd}$ concentration is higher at the surface than what would be expected from the bulk composition. Pd is expected to segregate toward the surface. ${ }^{8,9}$ The focusing area of the energy analyzer used for ISS is larger than the spot size of $1 \mathrm{~mm}$. Hence $\mathrm{Al}$ and $\mathrm{O}$ are expected to be present in all spectra. The large area sampled by the energy analyzer could also explain the small amount of $\mathrm{Ni}$ present in the spectrum for spot 1 and the small amount of Pd present in the spectrum for spot 9. The relatively high signal-to-noise ratio is caused by the use of a small ion current. It was important to minimize damage to the sample in order to be able to do sputter profiling afterwards.

Finally, sputter profiling was carried out on some of the spots. Figure 13 shows a sputter profile for spot 2 (one of the spots with the most active metal composition). The composition was calculated from peak to peak values obtained from differentiated Auger spectra. ${ }^{19}$ The sensitivity factors were obtained from Ref. 19, and not from a calibration measurement. Hence, the composition must be regarded as an estimate.

From the profile it seems that the Ni concentration increases and that the $\mathrm{Pd}$ concentration decreases somewhat with the depth. This could be due to variation in the relative deposition rates during manufacture of the sample, or to preferential sputtering. The oxide layer between the deposited metal layer and the Al bulk is clearly visible in the profile. It also seems as if aluminum oxide tends to replace 
Pd on the surface. This is expected because of the low surface energy of oxides. ${ }^{20}$

It is also clear that there are $\mathrm{Al}$ and $\mathrm{O}$ present throughout the metal layer, as might be expected if there are cracks in the metal film. The amount of $\mathrm{Al}$ is, however, larger than might be expected if it had been present as aluminum oxide. (This conclusion does not change for any reasonable variation in the sensitivity factors.) This indicates that metallic aluminum has penetrated the oxide layer and alloyed with $\mathrm{Pd}$ and $\mathrm{Ni}$. $\mathrm{Ni}-\mathrm{Al}$ and $\mathrm{Pd}-\mathrm{Al}$ alloys are very stable. ${ }^{21}$ There is thus a strong driving force for $\mathrm{Al}$ to move through any cracks or defects in the oxide film.

Sputter profiles were also made on spots 1 (pure Pd) and 9 (pure $\mathrm{Ni}$ ). The concentration of aluminum and oxygen was roughly the same as for spot 2 .

We have not been able to find other studies of the catalytic properties of $\mathrm{Ni} / \mathrm{Pd}(/ \mathrm{Al})$ alloys. The presence of an optimum for the hydrogen deuterium exchange reaction must be considered a preliminary result since no further testing has been done and it is beyond the scope of this article. The example does, however, illustrate the importance of postreaction surface analysis in catalysis research rather well.

\section{DISCUSSION}

The apparatus was used for studies of $\mathrm{CO}$ oxidation, $\mathrm{H}_{2}-\mathrm{D}_{2}$ exchange, and water formation reactions on a number of different metal surfaces. (Apart from the test of the delay time for the high-pressure measurements, there are no data on the water formation reaction included here.) The metals evaporated so far are $\mathrm{Ni}, \mathrm{Pd}, \mathrm{Ag}, \mathrm{Au}$, and $\mathrm{Cu}$. At most, two metals have been mixed in a single spot so far.

A complete cycle of evaporation, surface analysis, highpressure testing, and surface analysis can be carried out in less than a week, at least if the number of spots is less than 20 and the high pressure measurements are performed at one point per spot. Sample manufacturing is the most timeconsuming step, since metal deposition has to be carried out manually. Automation of the deposition step, so that deposition sequences could be programmed and carried out overnight, would speed up the work significantly. This would require some modifications of the electronics for the evaporator in order to make it more stable and new control software for the evaporation.

The ultrahigh vacuum lock is a critical part of the apparatus, but it has worked very well so far. The pressure in the main chamber remains in the low $10^{-10}$ Torr region also when the high-pressure cell is filled with gas at atmospheric pressure. The copper gasket of the lock has been used for up to 50 closing/opening cycles without leaking. Care should, however, be taken that the manipulator is at the same angular position every time.

The lateral resolution of the high-pressure measurements has turned out to be better than expected. It seems that the spillover of products from one spot to another is negligible if the distance between the spots is more than $0.7 \mathrm{~mm}$, at least under the conditions used so far. There is, however, a tradeoff between lateral resolution and sensitivity. To counteract diffusion of products formed on adjacent spots a high gas velocity is desirable. Increasing the velocity will unfortunately also lower the product concentration at the tip of the capillary, and hence give a higher level of detection in the measurement.

The measurement should be carried out as close to the sample surface as possible, since the product concentration decreases rapidly with distance from the surface. In order to avoid crashing the gas sampling nose into the sample, the distance should not be less than about $0.2 \mathrm{~mm}$.

The maximum number of $1 \mathrm{~mm}$ diam spots that can be studied on a sample with a diameter of $10 \mathrm{~mm}$ is about 20 if the separation between them is to be more than $1 \mathrm{~mm}$. A larger substrate and/or smaller spots should make it possible to study at least 50 spots in a single measurement cycle. Decreasing the spot size will, however, give lower sensitivity of the measurement. By experience, a spot $0.5 \mathrm{~mm}$ in diameter will give about half the product signal compared to a spot $1 \mathrm{~mm}$ in diameter.

The energy analyzer used for XPS and ISS can, at present, not focus on an area smaller than about $1.5 \mathrm{~mm}$ in diameter. The lateral resolution of XPS and ISS is thus a limitation for the number of spots that can be studied in a single measurement. The AES analysis equipment has proved itself very useful, because of its high lateral resolution.

The high lateral resolution of the high-pressure measurements makes it possible to study the catalytic activity of a specific, small area on a surface also in the viscous flow regime. This could be useful when studying single crystal surfaces, since the catalytic activities of different index planes can be measured independently of each other. It is also an advantage that the measurements are rather insensitive to background activity in the reactor, as long as it is not related to the gas inlet tube.

\section{ACKNOWLEDGMENTS}

The authors would like to express their great appreciation of the work done by Jan Fredriksen and Hans-Christian Sørensen who constructed the apparatus. The Danish Research Council is gratefully acknowledged for funding this project.

${ }^{1}$ S. Senkan, Angew. Chem., Int. Ed. 40, 312 (2001).

${ }^{2}$ A. Hagemeyer, B. Jandeleit, Y. Liu, D. M. Poojary, H. W. Turner, A. F. Volpe, Jr., and W. H. Weinberg, Appl. Catal., A 221, 23 (2001).

${ }^{3}$ P. Cong et al., Angew. Chem., Int. Ed. 38, 484 (1999).

${ }^{4}$ M. Orschel, J. Klein, H.-W. Schmidt, and W. F. Maier, Angew. Chem., Int. Ed. 38, 2791 (1999).

${ }^{5}$ P. Thormählen, Thesis No. 1696, Chalmers University of Technology, 2001.

${ }^{6}$ J. H. Sinfelt, Bimetallic Catalysts: Discoveries, Concepts, and Applications (Wiley, New York, 1983).

${ }^{7}$ F. Besenbacher, I. Chorkendorff, B. S. Clausen, B. Hammer, A. M. Molenbroek, J. K. Nørskov, and I. Stensgaard, Science 279, 1913 (1998).

${ }^{8}$ A. Christensen, A. V. Ruban, P. Stoltze, K. W. Jacobsen, H. L. Skriver, and J. K. Nørskov, Phys. Rev. B 56, 5822 (1997).

${ }^{9}$ A. V. Ruban, H. L. Skriver, and J. K. Nørskov, Phys. Rev. B 59, 15990 (1999).

${ }^{10}$ A. Ruban, B. Hammer, P. Stoltze, H. L. Skriver, and J. K. Nørskov, J. Mol. Catal. A: Chem. 115, 421 (1997).

${ }^{11}$ R. C. Regeberg and I. Chorkendorff, Catal. Lett. 77, 207 (2001).

${ }^{12}$ J. K. Nørskov et al., J. Catal. 209, 275 (2002).

${ }^{13}$ J. Nerlov and I. Chorkendorff, J. Catal. 181, 271 (1999). 
${ }^{14}$ B. Kasemo, Rev. Sci. Instrum. 50, 1602 (1979).

${ }^{15}$ C. T. Campbell, Adv. Catal. 36, 1 (1989).

${ }^{16}$ M. Johansson, I. Lundström, and L.-G. Ekedahl, Rev. Sci. Instrum. 71, 3513 (2000).

${ }^{17}$ M. Johansson and L.-G. Ekedahl, Appl. Surf. Sci. 180, 27 (2001).

${ }^{18}$ N. M. Markovic and P. N. Ross, Cattech 4, 110 (2000).

${ }^{19}$ L. E. Davis, N. C. MacDonald, P. W. Palmberg, G. E. Riach, and R. E.
Weber, Handbook of Auger Electron Spectroscopy, 2nd ed. (Physical Electronics Division, Perkin Elmer Corporation, Eden Prairie, MN, 1976).

${ }^{20}$ G. A. Somorjai, Introduction to Surface Chemistry and Catalysis (Wiley, New York, 1994).

${ }^{21}$ F. R. de Boer, R. Boom, W. C. M. Mattens, A. R. Miedama, and A. K. Niessen, Cohesion in Metals. Transition Metal Alloys (North-Holland Physics, Amsterdam, 1988). 